\title{
Ellagic Acid, an Anticarcinogen in Fruits, Especially in Strawberries: A Review
}

\author{
John L. Maas' and Gene J. Galletta ${ }^{2}$ \\ Fruit Laboratory, U.S. Department of Agriculture, Agricultural Research Service, Beltsville, MD 20705 \\ Gary D. Stoner ${ }^{3}$ \\ Department of Pathology, Medical College of Ohio, Toledo, OH 43699
}

\begin{abstract}
The various roles of ellagic acid as an anticarcinogenic plant phenol, including its inhibitory effects on chemically induced cancer, its effect on the body, occurrence in plants and biosynthesis, allelopathic properties, activity in regulation of plant hormones, formation of metal complexes, function as an antioxidant, insect growth and feeding inhibitor, and inheritance are reviewed and discussed in relation to current and future research.
\end{abstract}

Ellagic acid $\left(\mathrm{C}_{14} \mathrm{H}_{6} \mathrm{O}_{8}\right)$ is a naturally occurring phenolic constituent of many species from a diversity of flowering plant families. Interest in ellagic acid has increased greatly during the last decade due to its effectiveness as an antimutagen and anticarcinogen and its potential as an inhibitor of chemically induced cancer. Much has been learned since 1980 concerning the clinical attributes of ellagic acid, but relatively little is known about the physiological, genetic, and ecological aspects of ellagic acid and its naturally occurring derivatives in the plant. We know that ellagic acid is present in a wide variety of plants and its presence or absence maybe significant taxonomically, but we are only beginning to notice intraspecific variation.

Ellagic acid exists in plants in a great many derivative forms that differ in volubility, mobility, and reactivity in plant as well as in animal systems. Research has progressed at a rapid rate among medical research programs studying ellagic acid as a potential anticarcinogen or in blood clotting research. Exploring dietary sources of ellagic acid, the

Received for publication 10 Apr. 1990. The cost of publishing this paper was defrayed in part by the payment of page charges. Under postal regulations, this paper therefore must be hereby marked advertisement solely to indicate this fact.

'Plant Pathologist.

${ }^{2}$ Geneticist.

${ }^{3}$ Medical Research Pathologist and Director of Experimental Pathology. digestibility of natural forms of ellagic acid, and the distribution and organ accumulation or excretion in animal systems is in progress at several institutions. Recent interest in ellagic acid in plant systems has been largely for fruit-juice processing and wine industry applications. However, new studies also suggest that ellagic acid participates in plant hormone regulatory systems, allelopathic and autopathic effects, insect deterrent principles, and insect growth inhibition, all of which indicate the urgent need for further research to understand the roles of ellagic acid in the plant.

Carcinogenic and mutagenic factors, whether natural or products of industry, are ubiquitous in our environment. We may minimize our exposure to these carcinogens, but it is unlikely that they will ever be eliminated. Many efforts have been directed toward improving dietary habits to minimize cancer risk. In addition, the identification of naturally occurring anticarcinogens and antimutagens present in the diet is becoming increasingly important. A comprehensive knowledge of the cancer inhibitory properties of anticarcinogens necessitates an understanding of their action, and their physiological roles in plants.

\section{Ellagic acid: Anticarcinogen/antimutagen}

Ellagic acid has shown promise as an inhibitor of chemically induced cancer in invivo studies with rats and mice and in invitro studies with rat, mouse, and human tissue explants (Table 1). Antimutagenicity studies are generally done by assessing the inhibition by ellagic acid of potentially mutagenic chemicals in cultures of the bacterium Salmonella typhimunium.

Data have been reviewed on the effectiveness of ellagic acid as an anticarcinogen and antimutagen and on its mode of action as an inhibitor of chemically induced cancer (De Flora and Ramel, 1988; Hayatsu et al., 1988; Stoner, 1989).

\section{Mode of inhibition}

The inhibition of cancer by ellagic acid appears to occur through the following mechanisms:

a. Inhibition of the metabolic activation of carcinogens. For example, ellagic acid inhibits the conversion of polycyclic aromatic hydrocarbons [e.g., benzo (a) pyrene, 7,12dimethylbenz $(a)$ anthracene, and 3-methylcholanthrene], nitroso compounds (e.g., $N$ nitrosobenzylmethylamine and $N$-methyl- $N$ nitrosourea), and aflatoxin $\mathrm{B}_{1}$ into forms that induce genetic damage (Dixit et al., 1985; Teel et al., 1985; Mandal et al., 1987, 1988).

$b$. Carcinogen detoxification by stimulation of enzyme (e.g., glutathione s-transferase) activity is increased toward benzo $(a)$ pyrene-4,5oxide and 1-chloro-2,4-dinitrobenzene substrates in mice (Das et al., 1985).

c. Binding to reactive metabolic forms of the carcinogen to form a harmless complex that is incapable of reacting with cellular DNA, i.e., acts as a scavenger. Ellagic acid reacts with benzo $(a)$ pyrene diol epoxide by taking a sterically favorable position to form a covalently linked product in which the reactive epoxide ring of the pyrene is opened, rendering the carcinogen harmless (Sayer et al., 1982).

d. Occupation of sites in DNA that might otherwise react with carcinogens or their metabolizes. Ellagic acid inhibited the binding of $N$-methyl- $N$-nitrosourea to salmon sperm DNA by reacting with the $\mathrm{O}^{6}$ position in quanine and preventing methylation at that site (Dixit and Gold, 1986; Teel, 1986).

\section{Conflicting evidence}

Although ellagic acid shows promise as an inhibitor of chemically induced cancer, conflicting data have been presented in the literature on its effectiveness in preventing carcinogenesis or even DNA-adduct formation (Table 1). The high affinity of the strongly nucleophilic 4-OH group for electrophilic 
Table 1. Anticarcinogenic and antimutagenic activity of ellagic acid.

\begin{tabular}{|c|c|c|c|}
\hline Carcinogen & Tissue: donor & Response $^{2}$ & Reference \\
\hline \multirow[t]{8}{*}{ Benzo (a) pyrene } & Skin; rat & $\mathrm{AC}$ & Del Tito et al., 1983 \\
\hline & Lung explants; mouse & $\mathrm{AC}$ & $\begin{array}{l}\text { Dixit et al., 1985; } \\
\text { Teel et al., } 1985\end{array}$ \\
\hline & Skin; mouse & $\mathrm{AC}$ & Chang et al., 1985 \\
\hline & Skin explant; mouse & $\mathrm{AC}$ & Mukhtar et al., 1984b \\
\hline & Lung, skin; mouse & $\mathrm{AC}$ & Lesca, 1983 \\
\hline & Lung explant; human & $\mathrm{AC}$ & Teel et al., 1986a, 1986b \\
\hline & Salmonella (Ames) test & AM & Wood et al., 1982 \\
\hline & Lung, skin; mouse & $\mathrm{NE}$ & Smart et al., 1986a \\
\hline \multirow[t]{2}{*}{ Aflatoxin $\mathrm{B}_{1}$} & $\begin{array}{l}\text { Salmonella (Ames) test } \\
\text { Tracheobronchial }\end{array}$ & $\mathrm{AM}$ & $\begin{array}{l}\text { San and Chan, 1987; } \\
\text { Mandal et al., } 1987\end{array}$ \\
\hline & explants; rat, human & $\mathrm{AC}$ & Mandal et al., 1987 \\
\hline \multicolumn{4}{|l|}{ 7,12-Dimethylbenz } \\
\hline (a) anthracene & Mammary; rat & $\mathrm{NE}$ & Singletary and Liao, 1989 \\
\hline \multirow[t]{2}{*}{ Nitroso compounds } & Rat & $\mathrm{AC}$ & $\begin{array}{l}\text { Barth and Fox, 1988; } \\
\text { Mandal et al., 1988, } 1990\end{array}$ \\
\hline & Salmonella (Ames test) & $\mathrm{AM}$ & Dixit and Gold, 1986 \\
\hline \multirow[t]{2}{*}{ 3-Methylcholanthrene } & Skin; mouse & AT & Mukhtar et al., 1984a, 1986 \\
\hline & Skin; mouse & NE & Smart et al., $1986 b$ \\
\hline$N$-2-fluorenvIacetamide & Liver: rat & $\mathrm{AC}$ & Tanaka et al., 1988 \\
\hline
\end{tabular}

${ }^{2} \mathrm{AC}=$ anticarcinogenic effect; $\mathrm{AM}=$ antimutagenic effect; $\mathrm{AT}=$ antitumorigenic; $\mathrm{NE}=$ no $\mathrm{AC}$ or AM effects detected.

metabolizes that are non-DNA-reactive substances may effectively remove ellagic acid from biological systems and prevent it from acting as an anticarcinogen (Hayatsu et al., 1988). Absorption of ellagic acid into the body from a dietary source also appears to be limited. Ellagic acid fed orally to mice was found to be poorly absorbed and is eliminated as free ellagic acid and in conjugated forms (Tee] and Martin, 1988; Smart et al., 1986a), which may prevent tissues from attaining sufficiently high concentrations for it to be effective as an in-vivo anticarcinogen. Synthetic lipophilic derivatives of ellagic acid, especially 3- $o$-decylellagic acid, have greater affinities for lung and other tissues than has ellagic acid proper (Smart et al., 1986a).

\section{Human immunodeficiency virus inhibition}

Ellagic acid and some ellagitannins have shown inhibitory properties against replication of human immunodeficiency viruses (HIV) (Asanaka et al., 1988; Take et al., 1989) and of avian myeloblastosis virus (AMV) reverse transcriptase and cellular DNA polymerases $\boldsymbol{\alpha}$ and $\boldsymbol{\beta}$ (Take et al., 1989). Ellagic acid, unlike antibiotics such as Colistin or Enduracidine A, inhibits DNA polymerases nonspecifically. The antiviral activity of some ellagitannins may be due to inhibition of adsorption of HIV onto cells, as well as inhibition of reverse transcriptase activity (Asanaka et al., 1988; Take et al., 1989). Studies by Asanaka et al. (1988) with mice suggest that the ellagitannin oenotherin B may be effectively used by oral administration for inhibition of HIV and herpes virus.

\section{Other effects on the body}

Ellagic acid also has been found to control hemorrhage in animals (Girolami et al., 1966) and humans (Cliffton, 1967). In promoting clotting, ellagic acid activates the Hageman clotting factor (Factor XII) in blood (Bock et al., 1981). Ellagic acid is used widely in blood research to study factors affecting clotting, or thrombosis. It also may have some hypotensive (lowering blood pressure) and sedative effects according to preliminary research with rodents (Bhargava et al., 1968).

\section{Occurrence in plants}

Ellagic acid is a naturally occurring phenolic constituent of many flowering plant species (Bate-Smith, 1961 b). In the family Rosaceae (Bate-Smith, 1961a) and in the Fagaceae (Giannasi and Niklas, 1981), ellagic acid has been used as a chemotaxonomic guide. In the Rosaceae, it was found to be widely distributed in the subfamily Potentilleae (e.g, species of Potentilla, Comarella, Duchesnea, and Fragaria) and in the closely related genera Rubus, Geum, and Waldsteinia. Ellagic acid was also detected in the Rosaceous genera Purshia, Filipendula, Acaena, Alchemilla, Agrimonia, Poterium, and Rosa, but not among >70 Prunus spp. examined. These early studies focused on determining the presence of ellagic acid and were not quantitative. Recent studies have focused on quantification of ellagic acid in human dietary sources, especially fruits and nuts (Boyle and Hsu, 1990; Daniel et al., 1989; Maas et al., 1991; Wang et al., 1990).

Ellagic acid is a derivative of gallic acid, a trihydroxybenzoic acid, and its presence indicates a close relationship with plants possessing the trihydroxyflavonoid constituents, myricetin and leucodelphinidin. This relationship was found to hold for many members of the Saxifragaceae, Cunoniaceae, and Myrothamnaceae that are closely related to the Rosaceae. However, while members of the Lcguminosae possess trihydroxy substituted phenolics, they lack ellagic acid (Bate-Smith, 1961a).

\section{Biosynthesis}

Chemically, ellagic acid (Fig. 1) is 2,3,7,8tetrahydroxy[1]benzo-pyrano-[5,4,3-cde] [1] benzopyran-5,10-dione, $\mathrm{C}_{14} \mathrm{H}_{6} \mathrm{O}_{8}$, with a molecular weight of 302.19. It can be prepared from natural sources (Eucalyptus bark, walnuts, etc.) by sodium persulfate oxidation of gallic acid or by acid hydrolysis of crude tannin (Zee-Cheng and Cheng, 1986). In nature, ellagic acid may occur in free form, but more commonly in the form of ellagitarmins as esters of the diphenic acid analog on glucose.

Ellagic acid is formed by oxidation and dimerization of gallic acid; thus, it is a dilactone of the dimer of gallic acid. Oxidation is hastened by alkaline conditions, whereas hydrolysis and lactonization is favored by acidic conditions (Tulyathan et al., 1989). Ishikura et al. (1984) postulate two pathways for gallic acid formation; through B-oxidation of phenylpropanoid and through dehydrogenation of shikimic acid inRhus and Acer. The preferential pathway may be determined by leaf age, although temperature studies were not undertaken. The pathway from phenylalanine to cinnamic acid via phenyllactic acid is a possible pathway in strawberries. Activity of the delaminating enzyme phenylalanine ammonia-lyase (PAL) corresponds to the accumulation of anthocyanin in strawberry fruit (Given et al., 1988; Hyodo, 1971) and of flavonoids and cinnamic acids in strawberry leaf disks (Creasy, 1971); however, the relationship has not been determined between PAL activity and ellagic acid production.

Tannins and associated polyphenols in plant extracts have been widely studied for their medicinal and antimutagenic and anticarcinogenic properties (Hayatsu et al., 1988; Ito et al., 1989; Iwu and Anyanwu, 1982 Okuda et al., 1989; Sigman et al., 1984). Geraniin, a tannin constituent of many plants, including Geranium thunbergii Sieb. and Zucc., which is one of the most frequently used medicinal plants in Japan, produces ellagic acid abundantly by hydrolysis (Okuda et al., 1984). Geraniin, on hydrolysis, also produces gallic acid, which may form a dimer than can convert to ellagic acid.

Our studies (Maas et al., 1991) and the work of others (e.g. Daniel et al., 1989; Nemec, 1973) have shown that ellagic acid occurs in strawberries, but we do not know its

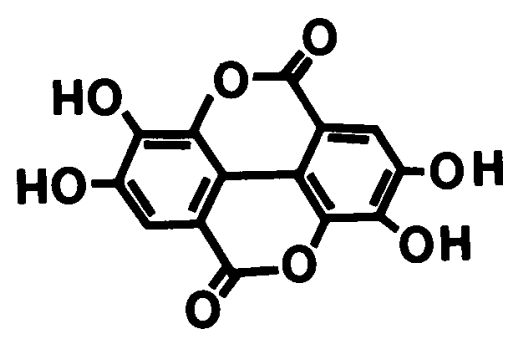

Fig. 1. Ellagic acid. 
function or route of synthesis in strawberries. In other plants, ellagic acid has been shown to occur in several derivative forms (Table 2).

The listing of derivatives of ellagic acid illustrates some of the complexity involved in determining the function of ellagic acid in plants, and which forms may be most effective as anticarcinogens.

\section{Allelopathy, fungistasis, and auto-inhibition}

Ellagic acid, as a derivative of gallic acid and as a phenol, probably shares some of the properties of these constituents. Hydrolyzable tannins, especially gallotannins, have been implicated as allelopathic agents (Rice, 1984). A recent review (Rice, 1984) of allelopathy lists the involvement of hydrolyzable tannins, including ellagic acid, as plant growth and seed germination inhibitors and growth inhibitors of $\mathrm{N}$-fixing and vitrifying bacteria. Ellagitannins produced by the white oak (Querqus alba L.) apparently protect the heartwood of the tree from fungal decay (Hart and Hillis, 1972). They suggest that the ellagitannins inhibit certain fungal enzymes due to their protein-binding capacities.

Ellagic acid was identified as one constituent of a Xanthium sp. exhibiting allelopathy (Inam et al., 1987). However, ellagic acid by itself was ineffective in inhibiting root growth or protein synthesis of lettuce seedlings, while ferulic and cinnamic acids were effective (Cameron and Julian, 1980; Krogmeier and Bremner, 1989). These studies do

Table 2. Examples of naturally occurring derivatives of ellagic acid.

$3,4^{\prime} 4-\dot{o}$-trimethylellagic acid ${ }^{2}$

$3,4,5,5^{\prime}$-o-tetramethyl-3', $4^{\prime}-0,0$ methylidenecoruleoellagic acid

3,4,5-o-trimethyl-3', $4^{\prime}-0,0$-methylideneflavellagic acid $^{2}$

3,3'-4-tri-o-methylellagic acidy

$3,4,4^{\prime}$-tri-o-methylellagic acidy

$3,3^{\prime}$-di-o-methylellagic acid $4^{\prime}$-rutinoside ${ }^{x}$

3,4,3'-tri-o-methylellagic acid ${ }^{\mathbf{x}}$

$5^{\prime}$-methoxy-3,4,3'-tri-o-methylflavellagic acid ${ }^{w}$

$3,4,3^{\prime}$-tri-o-methylflavellagic acid ${ }^{*}$

ellagic acid $3,3^{\prime}$-di-o-methyl ether

tri-o-methylellagic acid"

3,3'-di-o-methylellagic acid 4'-beta-D glucoside'

tetramethylellagic acids

tetra-o-methylellagic acidr

${ }^{2}$ From Agrostistachys hookeri; 3,3',4-o-trimethylellagic acid cytotoxic to cultured P-388 lymphocytic leukemia cells. Choi et al., 1988.

${ }^{y}$ From chestnut (Castanea sp.) cuttings; inhibits rooting of cuttings. Vieitez et al., 1987.

×From Euphorbia acaulis rhizomes. Bindra et al., 1988.

wFrom Rhabdodendron macrophyllum. Filho et al., 1985.

"From Polygonum hydropiper root. Fukuyama et al., 1983.

"From Acalypha indica leaves, twigs. Talapatra et al., 1981.

'From Anogeissus latifolia heartwood. Deshpande et al., 1981.

sFrom several species. Geevanada et al., 1980.

'From Geum elatum. Painuly et al., 1984. illustrate, however, that experimentation has been done mostly with ellagic acid in its free form and not with glycoside derivatives such as those produced by the plant. Auto-inhibition of rooting in chestnut tree cuttings was related to the presence of 3,3,4-tri- $o$-methylellagic acid (Vieitez et al., 1987; Vieitez and Ballester, 1988). In tests with beans, this ellagic acid derivative reduced the number of roots by $32 \%$ when added to the rooting medium at $10^{-5} \mathrm{M}$. When added to indoleacetic acid (IAA) at equamolar concentrations $\left(10^{-5} \mathrm{M}\right)$, the rooting activity of the auxin was reduced by 31.570. Similarly, phenolic exudates hamper in-vitro propagation of geraniums (Pelargonium $\times$ hortum). Hildebrandt and Harney (1989) identified ellagic acid and several gallic acid derivatives in exudates as responsible for the inhibitory activity. The naturally abundant tannin, geraniin, in Pelargonium spp. readily hydrolyzes to release ellagic and gallic acids (Okuda et al., 1984).

\section{Plant hormone regulation}

Ellagic acid was among the polyphenolic substances thought to function in the regulatory degradation system of IAA in strawberries (Runkova et al., 1972). Polyphenols in this system inhibited degradation of IAA by peroxidases, whereas monophenols (e.g., $p$-hydroxyphenylacetic acid and $p$-hydroxybenzoic acid) enhanced peroxidase degradation of IAA in strawberry tissues. Forcing photosynthesis to occur at a high rate with illumination caused production of increased amounts of polyphenols, while low or no illumination favored degradation of polyphenols and synthesis of monophenols as an integral part of the IAA regulatory system.

\section{Metal complexes}

Because of the ability of its four phenolic groups to readily form complexes with metals, such as $\mathrm{Mg}$ and $\mathrm{Ca}$, ellagic acid can cause the formation of insoluble aggregates. These ellagic acid-metal ion complexes have been implicated in promoting blood clotting (Bock et al., 1981) and in causing harmful scale accumulation on metal surfaces in the wood pulping process (Hewitt and Nelson, 1965; Press and Hardcastle, 1969). In general, orthodihydroxyphenols chelate with many metals. Ellagic acid has been shown to form complexes with mono-, di-, and trivalent metals as well as with various organic solvents (Nelson, 1965); it also forms a fluorescent complex with sodium borate (borax) that was found to be useful for its identification in samples (Wolfbeis and Hochmuth, 1986).

\section{Antioxidant}

Their metal chelating capacity together with their ability to react with free radicals gives many polyphenols effective antioxidant properties. Ellagic acid has been shown to function as an antioxidant (Osawa et al., 1987; Suet al., 1988), that is, as an oxidative sub- strate. It can terminate oxidations mediated by free radicals in a system, thus protecting other constituents from oxidation. This may be the mechanism of MA degradation inhibition described above. The oxidation mechanisms of ellagic and gallic acids during wine aging and related food processing have been determined by Tulyathan et al. (1989). They present a scheme of gallic acid oxidation and dimerization and of dilactone (ellagic acid) formation to explain regenerative polymerization in wines as a natural process when wines are made alkaline (Singleton, 1987). Gallic acid and ellagitannins are extracted by ethanol, along with other phenols, in wine aged with white-oak heartwood cooperage (Quinn and Singleton, 1985). Ellagitannins extracted though barrel aging may survive for at least several years in the wine.

Ellagic acid also has been shown to act as an exogenous antioxidant. It-may prevent oxidation of edible oil, fats, methyloleate, lard, and soybean and performs as well as or better than $\alpha$ tocopherol or $t$-butylanisole (Dziedzic and Hudson, 1984; Kurechi and Kunugi, 1983). In mammalian systems, ellagic acid and its derivatives show inhibitory activity against lipid peroxidation in mitochondria and microsomes (Okuda et al., 1983) and the cytochrome P450-dependent monooxygenase system.

Preferential oxidation of polyphenolic constituents of the pellicle of the walnut (Juglans regia L.) may protect the walnut kernel against decomposition (Jurd, 1956). Complete hydrolysis of walnut pellicle tannins yielded $50 \%$ of its weight as ellagic acid, $15 \%$ as gallic acid, plus methyl gallate and a considerable amount of glucose.

\section{Insect growth and feeding inhibition}

Ellagic acid is an endogenous inhibitor of insect growth and a deterrent of insect feeding on certain plants (Klocke et al., 1986). Several semi-arid species of Geranium, Erodium, Tamarix, Quercus, Cistus, and Heliothis possess the ellagitannin, geraniin, which acts as a protoxin that releases insect growth inhibitors, particularly ellagic acid, upon hydrolysis. Ellagic acid inhibits growth of the polyphagous herbivorous tobacco budworm [Heliothis virescens (Fabr.) (Noctuidae)]. Klocke et al. (1986) have shown that several members of the rose family inhibit the growth of insects, e.g., species of Amelanchier, Cercocarpus, Rosa, and several other genera. Fragaria spp. were not included. However, several Fragaria chiloensis clones were shown recently to be resistant to root-chewing insects (Shanks et al., 1984).

Inhibition. mechanisms of ellagic acid to chewing insects and aphids may be quite different. For example, differential sensitivity among aphid species to several ellagitannins and related phenolic compounds and derivatives was shown in feeding-deterrent studies (Jones and. Klocke, 1987). The ellagitannins geraniin and pedunculagin were active against Schizaphis graminum and Myzus persicae, but not against Acrythosiphon pisum. Ellagic and 
gallic acids, however, were inactive against $M$. persicae and $A$. pisum.

\section{Inheritance}

The manner of ellagic acid inheritance is not known. Strawberry (Maas et al., 1991), and blackberry and apple (Maas et al., unpublished), and muscadine grape (Boyle and Hsu, 1990) cultivars differ in amounts of ellagic acid in tissues. We presume by analogy with other metabolizes that cultivar differences are characteristic of each cultivar and that inheritance of relative ellagic acid content has either a high general or high specific combining ability (Galletta and Maas, 1990). Analogous inheritance mechanisms could occur with, ascorbic acid (vitamin C) and total soluble carbohydrates. Since the major portion of ellagic acid is presumably derived from a single metabolic pathway through gallic acid, we may find in strawberry that specific combining ability is of greater importance than general combining ability in ellagic acid inheritance, just as with ascorbic acid inheritance. The same may be true for gallic acid and geraniin inheritance, but probably not for massed derivatives of either constituent (e.g., ellagitannins as a group). If this hypothesis is correct, breeding for high (or low) ellagic acid content of fruit, or any other structure, should be highly successful. However, one unexpected observation in our examination of strawberry tissues was that no correlation was found among ellagic acid contents of fruit pulp, achenes, and leaf tissue (Maas et al., 1990). This may indicate that selection for ellagic acid content can be highly specific for tissue type, e.g., for high fruit content but low leaf content, etc. The reverse situation may be advantageous in muscadine grapes where ellagic acid is one component of the troublesome phenolics extracted with juice for commercial processing (Boyle and Hsu, 1990; Spiers, 1988), and of precipitates in wine made from loganberry (Singleton et al., 1966).

\section{Literature Cited}

Asanaka, M., T. Kurimura, R. Kobayashi, T. Okuda, M. Mori, and H. Yokoi. 1988. Fourth Intl. Conf. Immunopharmacology. May 1988. Osaka, Japan. (Abstr.)

Barth, D.H. and C.C. Fox. 1988. Selective inhibition of methylbenzylnitrosamine-induced formation of esophageal $O^{6}$-methylguanine by dietaryellagic acid in rata. Cancer Res. 48:70887092.

Bate-Smith, E.C. 1961a. Chromatography and taxonomy in the Rosaceae, with special reference to Potentilla and Prunus. J. Linn. Soc. (Bet.) 58:39-54.

Bate-Smith, E.C. 1961b. The phenolic constituents of plants and their taxonomic significance. I. Dicotyledons. J. Linn. Soc. (Bet.) 58:95173.

Bhargava, U.C., B.A. Westfall, and D.J. Siehr. 1968.Preliminary pharmacology of ellagic acid from Juglans nigra (black walnut). J. Pharm. Sci. 57:1728-1732.

Bindra, R.S., N.K. Satti, and O.P. Suri. 1988. Isolation and structures of ellagic acid derivatives from Euphorbia acaulis .Phytochemistry (OXF) 27:2313-2316.
Bock, P.E., K.R. Srinivasan, and J.D. Shore. 1981. Activation of intrinsic blood coagulation by ellagicacid: insoluble ellagic acid-metal ion complexes are the activating species. Biochemistry 20:7258.

Boyle, J.A. and L. Hsu. 1990. Identification and quantificationofellagic acid in muscadine grape juice. Amer. J. Enol. Vitic. 41:43-47.

Cameron, H. J. and G.R. Julian. 1980. Inhibition of protein synthesis in lettuce (Lactuca sativa L.) by allelopathic compounds. J. Chem. Ecol. 6:989-995.

Chang, R. L., M.-T. Huang, A.W. Wood, C.-Q. Wong, H.L. Newmark, H. Yagi, J.M. Sayer, D.M. Jerina, and A.H. Conney. 1985. Effect of ellagic acid and hydroxylated flavonoids on the tumorigenicity of benzo[a]pyrene and $(+)$ -7b,8a-dihydroxy-9a,10a-epoxy-7,8,9,10-tetrahydroxybenzo[a] pyrene on mouse skin and in the newborn mouse. Carcinogenesis 6:11271132.

Choi, Y.-H., J. M. Pezzuto, A.D. Kinghorn, and N.R. Farnsworth. 1988. Ellagic acid derivatives of Agrostistachys hookeri. Planta Med. 54:511-513

Cliffton, E.E. 1967. The effects of ellagic acid on the coagulation mechanisms and on traumatic bleeding. Amer. J. Med. Sci. 254:483-490.

Creasy, L.L. 1971. Role of phenylalanine in the biosynthesis of flavonoids and cinnamic acids in strawberry leaf disks. Photochemistry 10:2705-2711.

Daniel, E.M., A.S. Krupnick, Y.-H. Heur, J.A. Blinzler, R.W. Nims, and G.D. Stoner. 1989. Extraction, stability, and quantitation of ellagic acid in various fruits and nuts. J. Food Chem. Comp. Anal. 2::338-349.

Das, M., D.R. Bickers, and H. Mukhtar. 1985. Effect of ellagic acid on hepatic and pulmonary xenobiotic metabolism in mice: studies on the mechanism of its anticarcinogenic action. Carcinogenesis 6:1409-1413.

De Flora, S. and C. Ramel. 1988. Mechanisms ofinhibitorsof mutagenesis and carcinogenesis. Classification and overview. Mutation Res. 202:285-306.

Del Tito, B.J., Jr., H. Mukhtar, and D.R. Bickers. 1983. Inhibition of epidermal metabolism and DNA-binding of benzo[a]pyrene by ellagic acid. Biochem. Biophys. Res. Comm. 114:388394

Deshpande, V.H. and A.D. Patil. 1981. Chemical constituents of Anogeissus latifolia heartwood: isolation of 3,3'-diemethylellagic acid-4'-ß3D-glucoside. Ind. J. Chem. 20B:1010.

Dixit, R. and B. Gold. 1986. Inhibition of $N$ methyl- $N$-nitrosourea - induced mutagenicity and DNA methylation by ellagic acid. Proc. Natl. Acad. Sci. (USA) 83:8039-8043.

Dixit, R., R.W. Teel, F.B. Daniel, and G.D. Stoner. 1985. Inhibition of benzo[a]pyrene and benzo (a) pyrene- trans -7,8-diol metabolism and DNA binding in mouse lung explants by ellagic acid. Cancer Res. 45:2951-2956.

Dziedzic, S.Z. and B.J.F. Hudson. 1984. Phenolic acids and related compounds as antioxidant for edible oils. Food Chem. 14:45-51.

Filho, W.W., A.I. Da Rocha, M. Yoshida, and O.R. Gottlieb. 1985. Ellagic acid derivatives from Rhabdodendron macrophyllum. Photochemistry 24:1991-1993.

Fukuyama, Y., T. Sate, I. Miura, Y. Aaakawa, and T. Takemoto. 1983. Hydropiperoside, a novel coumaryl glycoside from the root of $P o$ lygonum hydropiper. Photochemistry 22:549552.

Galletta, G.J. and J.L. Maas. 1990. Strawberry genetics. HortScience 25:871-879.

Geevananda, Y.A., P. Gunawardana, M.U.S. Sultanbawa, and S. Balasubramaniam. 1980.
Distribution of some tri-terpenes and phenolic compounds in the extractive of endemic Dipterocarpaceae of Sri-Lanka. Photochemistry 19:1099-1102.

Giannasi, D.E. and K.J. Nikfas. 1981. Comparative paleobiochemistry of some fossil and extant Fagaceae. Amer. J. Bot. 68:762-770.

Girolami, A., D. Agostino, and E.E. Cliffton. 1966. The effect of ellagic acid on coagulation in vivo. Blood 27:93-102.

Given, N. K., M.A. Venis, and D. Grieraon. 1988. Phenylalanine ammonia-lyase activity and anthocyaninsynthesisin ripening strawberry fruit. J. Plant Physiol. 133:25-30.

Hart, J.H. and W.E. Hillis. 1972. Inhibition of wood-rotting fungi by ellagitannins in the heartwood of Querqus alba. Phytopathology 62:620626.

Hayatsu, H., S. Arimoto, and T. Negishi. 1988. Dietary inhibitors of mutagenesis and carcinogenesis. Mutation Res. 202:429-446.

Hewitt, D.G. and P.F. Nelson. 1965. Ellagic acid and the pulping of Eucalypts. Part I. Some aspects of the chemistry of ellagic acid. Holzforschung 19:97-101.

Hildebrandt, V. and P.M. Hamey. 1989. Identity of a phenolic exudate inhibitor from geranium plants. Can. J. Plant Sci. 69:569-575.

Hyodo, H. 1971. Phenylalanine ammonia lyase in strawberry fruits. Plant\& Cell Physiol. 12:989991.

Inam, B., F. Hussain, and F. Bane. 1987. Allelopathic effects of Pakistani weeda; Xanthium strumarium L. Pak. J. Sci. Ind. Res. 30:530533.

Ishikura, N., S. Hayashida, and K. Tazaki. 1984. Biosynthesisofgallicand ellagic acids with ${ }^{14} \mathrm{C}-$ labeled compounds in Acer and Rhus leaves. Bet. Msg. Tokyo 97:355-367.

Ito, Y., S. Ohnishi, and K. Fujie. 1989. Chromosome aberrations induced by aflatoxin $B_{1}$ in rat bone marrow cells in vivo and their suppression by green tea. Mutation Res. 222:253-261.

Iwu, M.M. and B.N. Anyanwu. 1982. Anti-inflammatory and anti-arthritic properties of Terminalia ivorensis. Fitoterapia 53:25-34.

Jones, K.C. and J.A. Klocke. 1987. Aphid feeding deterrency of ellagitannins, their phenolic hydrolysis products, and related phenolic derivatives. Entomol. Expt. Appl. 44:229-234.

Jurd, L. 1956. Plant polyphenols. I. The polyphenolic constituents of the pellicle of the walnut (Juglans regia). J. Amer. Chem. Soc. 78:3445-3448.

Klocke, J.A., B. VanWagenen, and M.F. Balandrin. 1986. The ellagitannin geraniin and its hydrolysisproducts isolated as insect growth inhibitorsfromsemi-arid land plants. Photochemistry 25:85-91.

Kurechi, T. and A. Kunugi. 1983. Studies on the antioxidant. XVII: Photooxidation products of concomitantly used butylate hydroxyanisole. J. Amer. Oil Chem. Soc. 60:109-113.

Krogmeier, M.J. and J.M. Bremner. 1989. Effects of phenolic acids on seed germination and seedlinggrowth in soil. Biol. Fertil. Soils 8:116122.

Lesca, P. 1983. Protective effects of ellagic acid and other plant phenols on benzo[a]pyrene-inducedneoplasiainmice.Carcinogenesis 4:16511653.

Maas, J. L., S.Y. Wang, and G.J. Galletta. 1991. Evaluationofstrawberrycultivarsforellagicacid content. HortScience 26:66-68.

Mandal, S., A. Ahuja, N.M. Shivapurkar, S.-J. Cheng, J.D. Groopman, and G.D. Stoner. 1987. Inhibition of aflatoxin B, mutagenesis in Salmonella typhimurium and DNA damage in cultured rat and human tracheobronchial tissues by ellagic acid. Carcinogenesis 8:1651-1656. 
Mandal, S., N.M. Shivapurkar, A.J. Galati, and G.D. Stoner. 1988. Inhibition of $N$-nitrosobenzylmethylamine metabolism and DNA binding in cultured rat esophagus by ellagic acid. Carcinogenesis 9:1313-1316.

Mandal, S. and G.D. Stoner. 1990. Inhibition of $N$-nitrosobenzylmethylamine-induced esophageal tumorigenesis in rats by ellagic acid. Carcinogenesis 11:55-61.

Mukhtar, H., M. Das, and D.R. Bickers. 1986. Inhibition of 3-methylcholanthrene-induced skin tumorigenicity in $\mathrm{BALB} / \mathrm{C}$ mice by chronic oral feeding of trace amounts of ellagic acid in drinking water. Cancer Res. 46:2262-2265.

Mukhtar, H., M. Das, B.J. Del Tito, Jr., and D.R. Bickers. 1984a. Protection against 3methlcholanthrene-induced skin tumorigenesis in Balb/C mice by ellagic acid. Biochem. Biophys. Res. Comm. 119:751-757.

Mukhtar, H., B.J. Del Tito, Jr., C.L. Marcelo, M. Das, and D.R. Bickers. 1984b. Ellagic acid: a potent naturally occurring inhibitor of benzo[a]pyrene metabolism and its subsequent glucuronidation, sulfation and covalent binding to DNA in cultured BALB/C mouse keratinocytes.Carcinogenesis 5:1565-1571.

Nelson, P.F. 1965. Ellagic acid and the pulping of Eucalypts. Part II. Complexes of ellagic acid with cations and solvents. Holzforschung 19:102-105.

Nemec, S. 1973. Phenolics in the strawberry root. Ann. Bot. 37:935-941.

Okuda, T., Y. Kimura, T. Yoshida, T. Hatano, H. Okuda, and S. Arichi. 1983. Studies on the activities of tannins and related compounds from medicinal plants and drugs. L Inhibitory effects on lipid peroxidation in mitochondria and microsomes of liver. Chem. Pharm. Bul. 31:16251631.

Okuda, T., K. Mori, and H. Hayatsu. 1984. Inhibitory effect of tannins on direct-acting mutagens. Chem. Pharm. Bul. 32:3755-3758.

Okuda, T., T. Yoshida, and T. Hatano. 1989. Ellagitannins as active constituents of medicinal plants. Planta Med. 55:117-122.

Osawa, T., A. Ide, J.-D. Su, and M. Namiki. 1987. Inhibition of lipid peroxidation by ellagic acid. J. Agr. Food Chem. 35:808-812.

Painuly, P., N. Varma, and J.S. Tandon. 1984. Constituents of Geum elatum. J. Natl. Prod. (Lloydia) 47:189.

Press, R.E. and-D. Hardcastle. 1969. Some physio-chemical properties of ellagic acid. J. Applied Chem. 19:247-251.

Quinn, M.K. and V.L. Singleton. 1985. Isolation and identification of ellagitannins from white oak wood and an estimation of their roles in wine. Amer. J. Enol. Vitic. 36:148-155.

Rice, E.L. 1984. Allelopathy. 2nd ed. Academic, New York.

Runkova, L.V., K.E. Lis, M. Tomaszewski, and R. Antoszewski. 1972. Function of phenolic substances in the degradation system of indole- 3-acetic acid in strawberries. Biol. Plant. (Praha) 14:71-81.

San, R.H.C. and R.I.M. Chan. 1987. Inhibitory effect of phenolic compounds on aflatoxin $B_{1}$ metabolism and induced mutagenesis. Mutation Res. 177:229-239.

Sayer, J.M., H. Yagi, A.W. Wood, A.H. Conney, and D.M. Jerina. 1982. Extremely facile reaction between the ultimate carcinogen benzo[a]pyrene-7,8 -diol 9,10-epoxide and ellagic acid. J. Amer. Chem. Soc. 104:5562-5564.

Shanks, C.H., Jr., D.L. Chase, and J.D. Chamberlain. 1984. Resistance of clones of wild strawberry, Fragaria chiloensis, to adult Otiorhynchus sulcatus and O. ovatus. Env. Entomol. 13:1042-1045.

Sigman, C.C., C.T. Helmes, J.R. Fay, P.L. Lundquist, and L.R. Perry. 1984. A study of chemicals in the wood and associated industries for selection of candidates for carcinogen bioassay; I. Naturally occurring wood chemicals. J. Env. Sci. Health A19:533-577.

Singletary, K. and C. Liao. 1989. Ellagic acid effects on the carcinogenicity, DNA-binding and metabolism of 7,12-dimethylbenzy(a)anthracene (DMBA). In Vivo 3:173-176.

Singleton, V.L. 1987. Oxygen with phenols and related reactions in musts, wines, and model systems: observations and practical implications. Amer. J. Enol. Vitic. 38:69-77.

Singleton, V.L., G.L. Marsh, and M. Coven. 1966. Identification of ellagic acid as a precipitate from loganberry wine. J. Agr. Food Chem. 14:5-8.

Smart, R.C., M.-T. Huang, R.L. Chang, J.M. Sayer, D.M. Jerina, and A.H. Conney. 1986a. Disposition of the naturally occurring antimutagenic plant phenol, ellagic acid, and its synthetic derivatives, 3- $o$-decylellagic acid and 3,3'di- $o$-methylellagic acid in mice. Carcinogenesis 7:1663-1667.

Smart, R.C., M.-T. Huang, R.L. Chang, J.M. Sayer, D.M. Jerina, A.W. Wood, and A.H. Conney. 1986b. Effect of ellagic acid and 3- $O$ declyellagic acid on the formation of benzo[a]pyrene-derived DNA adducts in vivo and on the tumorigenicity of 2-methylcholanthrene in mice. Carcinogenesis 7:1669-1675.

Spiers, J.M. 1988. Muscadine grape processing research. Proj. no. 6404-41000-001-00D, U.S. Dept. Agr., Agr. Res. Serv.

Stoner, G.D. 1989. Ellagic acid: A naturally occurring inhibitor of chemically-induced cancer. Proc. 1989 Ann. Mtg. Amer. Strawberry Growers Assn., Grand Rapids, Mich. p. 20-34.

Su, J.-D., T. Osawa, S. Kawakishi, and M. Namiki. 1988. Tannin antioxidants from Osbeckia chinemsis. Photochemistry 27:1315-1320.

Take, Y., Y. Inouye, S. Nakamura, H.S. Allaudeen, and A. Kubo. 1989. Comparative studies of the inhibitory properties of antibiotics on human immunodeficiency virus and avian myeloblastosis virus reverse transcriptases and cellular DNA polymerases. J. Antibiotics 42:107-115.
Talapatra, B., S. Goswami, and S.K. Talapatra. 1981. Acalphamide, a new amide \& other chemical constituents of Acalypha indica Linn. Ind. J. Chem. 20B:974-977.

Tanaka, T., H. Iwata, K. Niwa, Y. Mori, and H. Mori. 1988. Inhibitory effect of ellagic acid on $\mathrm{N}$-2-fluorenylacetamide-induced liver carcinogenesis in male $\mathrm{ACl} / \mathrm{N}$ rats. Japan. J. Cancer Res. (Gann) 79:1297-1303.

Teel, R.W. 1986. Ellagic acid binding to DNA as a possible mechanism for its antimutagenic and anticarcinogenic action. Cancer Lett. 30:329336.

Teel, R.W. and R.M. Martin. 1988. Disposition of the plant phenol ellagic acid in the mouse following oral administration by gavage. Xenobiotica 18:397-405.

Teel, R. W., R. Dixit, and G.D. Stoner. 1985. The effect of ellagic acid on the uptake, persistence, metabolism and DNA-binding of benzo[a]pyrene in cultured explants of strain A/ J mouse lung. Carcinogenesis 6:391-395.

Tee], R.W., G.D. Stoner, M.S. Babcock, R. Dixit, and K. Kim. 1986a. Benzo(a)pyrene metabolism and DNA-binding in cultured explants of human bronchus and in monolayer cultures of human bronchial epithelial cells treated with ellagic acid. Cancer Detection Prevention 9:5966.

Teel, R.W., M.S. Babcock, R. Dixit, and G.D. Stoner. 1986b. Ellagic acid toxicity and interaction with benzo[a]pyrerre and benzo[a]pyrene 7,8-dihydrodiol in human bronchial epithelial cells. Cell Biol. Toxicol. 2:53-62.

Tulyathan, V., R.B. Boulton, and V.L. Singleton. 1989. Oxygen uptake by gallic acid as a model for similar reactions in wines. J. Agr. Food Chem. 37:844-849.

Vieitez, F.J. and A. Ballester. 1988. Effect of etiolation and shading on the formation of rooting inhibitors in chestnut trees. Phyton (Buenos Aires) 48:13-20.

Vieitez, J., D.G.I. Kingston, A. Ballester, and E. Vieitez. 1987. Identification of two compounds correlated with lack of rooting capacity of chestnut cuttings. Tree Physiol. 3:247-256.

Wang, S.Y., J.L. Maas, E.M. Daniel, and G.J. Galletta. 1990. Improved HPLC resolution and quantification of ellagic acid from strawberry, blackberry and cranberry. HortSciencc 25:1078. (Abstr.)

Wolfbeis, O.S. and P. Hochmuth. 1986. The fluorescence of ellagic acid and its borax complex. Monatsch. Chemie 117:369-374.

Wood, A.W., M.-T. Huang, R.L. Chang, H.L. Newmark, R.E. Lehr, H. Yagi, J.M. Sayer, D.M. Jerina, and A.H. Conney. 1982. Inhibition of the mutagenicity of bay-region diol epoxides of polycyclic aromatic hydrocarbons by naturally occurring plant phenols: Exceptional activity of ellagic acid. Proc. Natl. Acad. (USA) 79:5513-5517.

Zee-Cheng, R. K.-Y. and C.C. Cheng. 1986. Ellagic acid. Drugs of the Future 11:1029-1033. 